\title{
Effects of Full-Moon Definition on Psychiatric Emergency Department Presentations
}

\author{
Varinder S. Parmar, ${ }^{1}$ Ewa Talikowska-Szymczak, ${ }^{1}$ Emily Downs, ${ }^{2}$ Peter Szymczak, \\ Erin Meiklejohn, ${ }^{2}$ and Dianne Groll ${ }^{1}$ \\ ${ }^{1}$ Department of Psychiatry, Queen's University, 752 King Street West, Kingston, ON, Canada K7L 4X3 \\ ${ }^{2}$ Department of Psychology, Queen's University, 99 University Avenue, Kingston, ON, Canada K7L 3N6 \\ Correspondence should be addressed to Varinder S. Parmar; vsp908@gmail.com
}

Received 30 October 2013; Accepted 18 December 2013; Published 12 January 2014

Academic Editors: C. Damsa and P. Eisenburger

Copyright (C) 2014 Varinder S. Parmar et al. This is an open access article distributed under the Creative Commons Attribution License, which permits unrestricted use, distribution, and reproduction in any medium, provided the original work is properly cited.

\begin{abstract}
Objectives. The lunar cycle is believed to be related to psychiatric episodes and emergency department (ED) admissions. This belief is held by both mental health professionals and the general population. Previous studies analyzing the lunar effect have yielded inconsistent results. Methods. ED records from two tertiary care hospitals were used to assess the impact of three different definitions of the full-moon period, commonly found in the literature. The full-moon definitions used in this study were 6 hours before and 6 hours after the full moon (a 12-hour model); 12 hours before and 12 hours after the full moon (a 24-hour model); and 24 hours before and after the day of the full moon (a 3-day model). Results. Different significant results were found for each full-moon model. Significantly fewer patients with anxiety disorders presented during the 12-hour and 24-hour models; however, this was not true of the 3-day model. For the 24-hour model, significantly, more patients presented with a diagnosis of personality disorders. Patients also presented with more urgent triage scores during this period. In the 3-day model, no significant differences were found between the full-moon presentations and the non-full-moon presentations. Conclusions. The discrepancies in the findings of full moon studies may relate to different definitions of "full moon." The definition of the "full moon" should be standardized for future research.
\end{abstract}

\section{Introduction}

The belief that the lunar cycle is associated with the onset and severity of psychiatric symptoms has persisted since the middle ages [1]. This belief still occurs in some mental health professionals, who report that the agitation of psychiatric symptoms induced by the full moon results in increased admissions, suicides, homicides, and emergency department (ED) visits [1-4]. Opinion surveys conducted with ED personnel also indicate the belief that the demand for patient services increases during the full moon $[4,5]$.

The belief that the lunar cycle influences the frequency and severity of emergency psychiatric presentations is clearly widespread. However, few studies conducted to date have found consistent evidence in support of a lunar effect [1$3,5-13]$. The bulk of lunar research has found no relationship between lunar activity and ED psychiatric presentations [510]. These findings suggest that psychiatric ED presentations are not influenced by the phases of the lunar cycle.

Despite being in the minority, some retrospective studies have found a relationship between the frequency of criminal behaviour or psychiatric crises and the lunar cycle [11, 12]. Templer and Veleber found that a disproportionate number of suicide attempts, emergency and counseling telephone calls, acute psychiatric hospital admissions, arrests, and schizophrenia hospital admissions occurred during the full and new moons [11]. Other researchers have found a relationship between criminal behavior and the lunar cycle. Several criminal offences including rape, robbery and assault, burglary, property and automobile theft, drunkenness, and disorderly conduct have been found to occur more frequently 3 days prior to and following the full moon than at other times 
during the lunar cycle $[2,3,12]$. The relationship between the lunar cycle and aggressive behavior is also contradictory; several studies have found an increase in aggressive behavior at the time of the full moon, while other, more robust, studies have found the opposite effect $[9,10,14]$. The results of these studies directly contradict the findings of other studies in this area which have not found evidence to support the lunar effect.

Thus, the research performed in this area to date does not demonstrate a consistent relationship between emergency psychiatric admissions and the lunar cycle. The response to this lack of consistency has been to replicate previous studies looking for different results. We, however, propose that these inconsistent results may be due to the wide variety of definitions of the "full-moon" timeframe used in previous lunar research.

Therefore, in this study, we analyzed the relationship between the lunar cycle and the frequency of emergency psychiatric presentations in one population using three different methods of defining the "full-moon" timeframe. In the first model, we defined the full-moon period as the 12 hours surrounding the full moon. In the second model, we defined the full moon as a 24-hour period including the 12 hours before and after the time of the full moon. In the third model, we defined the full-moon period as a three-day period consisting of 24 hours before and after the 24-hour period surrounding the time of the full moon.

These definitions of the full-moon period are found in lunar research because they are thought to ensure that the study captures both the potential direct effects of the full moon (12 hours) and the potential effect of the waxing and waning moon (24 hours and the 3 -day period). We hypothesized that each model will yield different psychiatric diagnoses and presentation characteristics (e.g., mode of arrival and triage severity) for ED presentations during the full-moon period specified by that model.

\section{Methods}

This study was conducted using data from two tertiary care centers in Kingston, Ontario. We obtained our data from an administrative database maintained by Hotel Dieu Hospital ( $\mathrm{HDH})$ and Kingston General Hospital (KGH). These databases recorded all presentations to the EDs of these hospitals. We included presentations if they were categorized as "Mental Health and Psychosocial Condition" over a fiveyear period. We included the following information about each presentation in our data set: date and time of presentation, triage severity, and mode of arrival. We also included the following patient characteristics: gender, marital status, age, and primary diagnosis.

We then grouped the primary diagnoses into the following diagnostic clusters: dementia, delirium and cognitive disorders; substance-related disorders; schizophrenia and psychotic disorders; mood disorders; adjustment disorders; anxiety disorders; somatoform and dissociative disorders; eating disorders; personality disorders; childhood disorders; and other disorders.
Next, we categorized ED presentations based on whether they occurred during the period defined by one of the fullmoon models that we tested. We calculated all of the fullmoon periods using the exact time of the full moon, which we obtained from tables available on the NASA website [15]. A total of 62 full moons occurred over the five-year period captured by the database. We coded each presentation in our data set as "full moon" if it occurred during the period specified by that model or "control" if it occurred outside the period.

In the 12-hour model, we defined all presentations that occurred within the 6 hours preceding or following the time of the full moon as "full-moon" presentations. In the 24-hour model, we defined all presentations that occurred within 12 hours preceding or following the time of the full moon as "full-moon" presentations. In the 3-day model, we defined all presentations that occurred 24 hours before or after the 24 hours surrounding the time of the full moon as "full-moon" presentations.

\section{Analysis}

We used SPSS version 20.0 to analyze the data. We conducted independent samples $t$-tests to compare demographic variables (including age, gender, triage score, and arrival method) and the frequency of presentation of the primary diagnostic clusters between "full moon" and "non-full moon" presentations for each full moon model. Statistical significance was considered to be $P<0.05$.

Prior to the commencement of this study, ethical approval was obtained from the Queen's University Health Sciences Research Ethics Board.

\section{Results}

A total of 9,967 presentations were made to the ED for Mental Health and Psychosocial Condition during the 5-year study period. Of the total population, $54 \%$ were male $(n=5,3867)$ and $46 \%$ were female $(4,580)$. The average age was 36.1 years $(\mathrm{SD}=19.0)$. The majority of individuals were walk-ins (58.4\%, $n=5,817)$, followed by ground ambulance $(34.6 \%$, $n=3,446)$, police $(6.6 \%, n=655)$, and then "other or missing" $(0.3 \%, n=29)$. Most $(n=5,436,54.5 \%)$ individuals had a triage code of " 3 " or "urgent", followed by " 4 " or "less urgent" ( $n=3,082,30.9 \%)$.

Demographics for the 12-hour, 24 hour, and 3-day full moon models can be found in Tables 1, 2, and 3 .

In the 12-hour full-moon model, we found that significantly fewer patients with anxiety disorders presented to the ED compared to the non-full-moon period $(\mathrm{M}=0.17 ; \mathrm{SD}=$ 0.38 versus $M=0.25 ; S D=0.43), P=0.016$.

In the 24-hour model, we again found that significantly fewer patients with anxiety presented during the full-moon period $(\mathrm{M}=0.19 ; \mathrm{SD}=0.40, \mathrm{M}=0.25 ; \mathrm{SD}=0.43)$ compared to patients who presented during the non-fullmoon period $P=0.019$. We also found that in the 24 hour model there were significantly more admissions for personality disorders $(\mathrm{M}=0.03 ; \mathrm{SD}=0.16)$ than during the 
TABLE 1: Frequencies and percentages for psychiatric ED presentations for the 12-hour model.

\begin{tabular}{|c|c|c|c|c|c|c|}
\hline \multirow{2}{*}{ Characteristic } & \multicolumn{3}{|c|}{$12 \mathrm{hr}$ full-moon period $(n=170)$} & \multicolumn{3}{|c|}{ All other times $(n=9797)$} \\
\hline & $n$ & $\mathrm{M}(\mathrm{SD})$ & Percent & $n$ & $\mathrm{M}(\mathrm{SD})$ & Percent \\
\hline Age & & $36.18(18.91)$ & & & $36.06(18.98)$ & \\
\hline \multicolumn{7}{|l|}{ Gender } \\
\hline Male & 97 & & 57.1 & 5289 & & 54.0 \\
\hline Female & 73 & & 42.9 & 4507 & & 46.0 \\
\hline \multicolumn{7}{|l|}{ Marital status } \\
\hline Married & 21 & & 12.5 & 1447 & & 15.0 \\
\hline Single & 100 & & 59.5 & 5951 & & 61.7 \\
\hline Divorced & 13 & & 7.7 & 613 & & 6.4 \\
\hline Separated & 6 & & 3.6 & 513 & & 5.3 \\
\hline Widowed & 6 & & 3.6 & 360 & & 3.7 \\
\hline Common-law & 22 & & 13.1 & 767 & & 7.9 \\
\hline \multicolumn{7}{|l|}{ Primary diagnosis } \\
\hline Dementia, delirium, and cognitive disorders & 3 & & 1.8 & 201 & & 2.1 \\
\hline Substance-related disorders & 75 & & 44.1 & 3848 & & 39.3 \\
\hline Schizophrenia and psychotic disorders & 11 & & 6.5 & 563 & & 5.7 \\
\hline Mood disorders & 17 & & 10 & 961 & & 9.8 \\
\hline Adjustment disorders & 18 & & 10.6 & 772 & & 7.9 \\
\hline Anxiety disorders & 29 & & 17.1 & 2464 & & 25.2 \\
\hline Somatoform and dissociative disorders & 3 & & 1.8 & 230 & & 2.3 \\
\hline Eating disorders & 0 & & 0 & 42 & & 0.4 \\
\hline Personality disorders & 3 & & 1.8 & 115 & & 1.2 \\
\hline Childhood disorders & 3 & & 1.8 & 295 & & 3 \\
\hline Others & 8 & & 4.7 & 305 & & 3.1 \\
\hline \multicolumn{7}{|l|}{ Arrival mode } \\
\hline Ground ambulance & 59 & & 34.7 & 3387 & & 34.6 \\
\hline Others & 1 & & 0.6 & 28 & & 0.3 \\
\hline Police & 12 & & 7.1 & 643 & & 6.6 \\
\hline Walk-in & 98 & & 57.6 & 5719 & & 58.4 \\
\hline \multicolumn{7}{|l|}{ Triage code } \\
\hline Emergent & 28 & & 16.5 & 936 & & 9.6 \\
\hline Less urgent & 55 & & 32.4 & 3027 & & 30.9 \\
\hline Nonurgent & 6 & & 3.5 & 444 & & 4.5 \\
\hline Resuscitation & 1 & & 0.6 & 33 & & 0.3 \\
\hline Unavailable & 0 & & 0.0 & 1 & & 0 \\
\hline Urgent & 80 & & 47.1 & 5356 & & 54.7 \\
\hline
\end{tabular}

non-full moon period $(\mathrm{M}=0.01 ; \mathrm{SD}=0.11) P=0.02$, and triage scores during the 24 -hour full moon period $(\mathrm{M}=3.22$; $\mathrm{SD}=0.73$ ) were significantly more urgent than triage scores during the non-full moon period $(\mathrm{M}=3.29 ; \mathrm{SD}=0.72)$ $P=0.045$. However, while the differences in the mean triage scores are statistically significant, the actual difference is quite small.

The 3-day model did not show any statistically significant differences between presentations that occurred during the full-moon period and the non-full-moon period.

\section{Discussion}

We analyzed three definitional models of the full-moon period within the same population and found different significant results for each model. The results of previous lunar research have been equally contradictory. The majority of studies conducted to date have found that the lunar cycle does not have a significant effect on psychiatric ED presentations [5-10]. However, a small number of studies have found the opposite; these results support the hypothesis that psychiatric 
TABLE 2: Frequencies and percentages for psychiatric ED presentations for the 24-hour model.

\begin{tabular}{|c|c|c|c|c|c|c|}
\hline \multirow{2}{*}{ Characteristic } & \multicolumn{3}{|c|}{$24 \mathrm{hr}$ full-moon period $(n=310)$} & \multicolumn{3}{|c|}{ All other times $(n=9657)$} \\
\hline & $n$ & $\mathrm{M}(\mathrm{SD})$ & Percent & $n$ & $\mathrm{M}(\mathrm{SD})$ & Percent \\
\hline Age & & $37.06(19.98$ & & & $36.03(18.95)$ & \\
\hline \multicolumn{7}{|l|}{ Gender } \\
\hline Male & 178 & & 57.4 & 5208 & & 53.9 \\
\hline Female & 132 & & 42.6 & 4448 & & 46.1 \\
\hline \multicolumn{7}{|l|}{ Marital status } \\
\hline Married & 39 & & 12.8 & 1429 & & 15 \\
\hline Single & 187 & & 61.3 & 5864 & & 61.6 \\
\hline Divorced & 17 & & 5.6 & 609 & & 6.4 \\
\hline Separated & 11 & & 3.6 & 508 & & 5.3 \\
\hline Widowed & 16 & & 5.2 & 350 & & 3.7 \\
\hline Common-law & 35 & & 11.5 & 754 & & 7.9 \\
\hline \multicolumn{7}{|l|}{ Primary diagnosis } \\
\hline Dementia, delirium, and cognitive disorders & 6 & & 1.9 & 198 & & 2.0 \\
\hline Substance-related disorders & 131 & & 42.3 & 3792 & & 39.3 \\
\hline Schizophrenia and psychotic disorders & 25 & & 8.1 & 549 & & 5.7 \\
\hline Mood disorders & 28 & & 9 & 950 & & 9.8 \\
\hline Adjustment disorders & 26 & & 8.4 & 764 & & 7.9 \\
\hline Anxiety disorders & 60 & & 19.4 & 2433 & & 25.2 \\
\hline Somatoform and dissociative disorders & 6 & & 1.9 & 227 & & 2.4 \\
\hline Eating disorders & 0 & & 0 & 43 & & 0.4 \\
\hline Personality disorders & 8 & & 2.6 & 110 & & 1.1 \\
\hline Childhood disorders & 8 & & 2.6 & 290 & & 3 \\
\hline Others & 12 & & 3.9 & 301 & & 3.1 \\
\hline \multicolumn{7}{|l|}{ Arrival mode } \\
\hline Ground ambulance & 110 & & 35.5 & 3336 & & 34.5 \\
\hline Others & 1 & & 0.3 & 28 & & 0.3 \\
\hline Police & 18 & & 5.8 & 637 & & 6.6 \\
\hline Walk-in & 179 & & 57.7 & 5638 & & 58.4 \\
\hline \multicolumn{7}{|l|}{ Triage code } \\
\hline Emergent & 44 & & 14.2 & 920 & & 9.5 \\
\hline Less urgent & 97 & & 31.3 & 2985 & & 30.9 \\
\hline Nonurgent & 8 & & 2.6 & 442 & & 4.6 \\
\hline Resuscitation & 1 & & 0.3 & 33 & & 0.3 \\
\hline Unavailable & 0 & & 0 & 1 & & 0 \\
\hline Urgent & 160 & & 51.6 & 5276 & & 54.6 \\
\hline
\end{tabular}

emergencies and other pathological behaviour (e.g., robbery and assault) are more likely to occur around the full moon $[2,3,12]$.

The results of our study seem to support the findings of both kinds of research. Consistent with the majority of lunar research, we found that the lunar cycle did not influence ED presentations in the 3-day model. However, in the 12-hour and 24-hour models, we found a significant effect of the lunar cycle such that the frequency of psychiatric ED presentations was reduced during the full moon. We also found that significantly more patients with a diagnosis of personality disorder presented during the $24 \mathrm{hr}$ full-moon period and that triage codes during this time tended to be more severe. These results support the minority of lunar research, which has found an effect of the lunar cycle. Our results are clearly contradictory and provide a good representation of the confusion that exists in lunar research. However, our study is the first of its kind conducted to test the validity of common lunar models used in lunar research within the same population. Our study may be used to provide an explanation for the conflicting findings about the relationship between the lunar cycle and the frequency or severity of psychiatric emergencies discovered by other researchers $[1,2,5,10]$. Our results indicate that the use of different definitional models 
TABLE 3: Frequencies and percentages for psychiatric ED presentations for the 3-day model.

\begin{tabular}{|c|c|c|c|c|c|c|}
\hline \multirow{2}{*}{ Characteristic } & \multicolumn{3}{|c|}{ 3-day full-moon period $(n=1016)$} & \multicolumn{3}{|c|}{ All other times $(n=8951)$} \\
\hline & $n$ & $\mathrm{M}(\mathrm{SD})$ & Percent & $n$ & $\mathrm{M}(\mathrm{SD})$ & Percent \\
\hline Age & & $35.72(18.79$ & & & $36.10(19.00)$ & \\
\hline \multicolumn{7}{|l|}{ Gender } \\
\hline Male & 540 & & 53.1 & 4846 & & 54.1 \\
\hline Female & 476 & & 46.9 & 4104 & & 45.9 \\
\hline \multicolumn{7}{|l|}{ Marital status } \\
\hline Married & 148 & & 14.8 & 1320 & & 15.0 \\
\hline Single & 603 & & 60.2 & 5448 & & 61.8 \\
\hline Divorced & 61 & & 6.1 & 565 & & 6.4 \\
\hline Separated & 54 & & 5.4 & 465 & & 5.3 \\
\hline Widowed & 46 & & 4.6 & 320 & & 3.6 \\
\hline Common-law & 89 & & 8.9 & 700 & & 7.9 \\
\hline \multicolumn{7}{|l|}{ Primary diagnosis } \\
\hline Dementia, delirium, and cognitive disorders & 20 & & 2.0 & 184 & & 2.1 \\
\hline Substance-related disorders & 407 & & 40.1 & 3516 & & 39.3 \\
\hline Schizophrenia and psychotic disorders & 70 & & 6.9 & 504 & & 5.6 \\
\hline Mood disorders & 95 & & 9.4 & 883 & & 9.9 \\
\hline Adjustment disorders & 77 & & 7.6 & 713 & & 8.0 \\
\hline Anxiety disorders & 248 & & 24.4 & 2245 & & 25.1 \\
\hline Somatoform and dissociative disorders & 21 & & 2.1 & 212 & & 2.4 \\
\hline Eating disorders & 5 & & 0.5 & 38 & & 0.4 \\
\hline Personality disorders & 13 & & 1.3 & 105 & & 1.2 \\
\hline Childhood disorders & 29 & & 2.9 & 269 & & 3.0 \\
\hline Others & 31 & & 3.1 & 282 & & 3.2 \\
\hline \multicolumn{7}{|l|}{ Arrival mode } \\
\hline Ground ambulance & 340 & & 33.5 & 3106 & & 34.7 \\
\hline Others & 3 & & 0.3 & 26 & & 0.3 \\
\hline Police & 72 & & 7.1 & 583 & & 6.5 \\
\hline Walk-in & 598 & & 58.9 & 5219 & & 58.3 \\
\hline \multicolumn{7}{|l|}{ Triage code } \\
\hline Emergent & 98 & & 9.6 & 866 & & 9.7 \\
\hline Less urgent & 308 & & 30.3 & 2774 & & 31 \\
\hline Nonurgent & 46 & & 4.5 & 404 & & 4.5 \\
\hline Resuscitation & 4 & & 0.4 & 30 & & 0.3 \\
\hline Unavailable & 0 & & 0.0 & 1 & & 0.0 \\
\hline Urgent & 560 & & 55.1 & 4876 & & 54.5 \\
\hline
\end{tabular}

of the full-moon period influences the significant results obtained. Future studies need to be clear on their definition of the "full-moon" period, so that the results of studies with similar definitions can be compared. Ideally, a standardized definition (or definitions) of the full-moon period should be adopted, thereby allowing for a true inter-study comparison. The ability to conduct this kind of inter-study comparison would allow researchers to generate conclusive results about the effect of the lunar cycle on ED presentations.

Although methodological issues may explain the conflicting research findings in this area, this does not explain why the belief in a lunar effect continues to be so widespread. One plausible explanation is that this belief is a cultural artifact, left over from the time before artificial lighting, when the lunar cycle had a real influence on the severity of bipolar and epileptic symptoms $[1,16]$. Before artificial lighting, it was too dark for people to be active after sunset during the waxing and waning phases of the lunar cycle [1]. The full moon provided an increase in the amount of nighttime illumination and caused a significant sleep disturbance as a result [1]. Recent research has shown that sleep disruptions of as little as 1.5 hours from baseline can induce mania and seizures in vulnerable people [16]. In addition, myths surrounding the influence of celestial bodies on human behavior have 
existed for centuries [17]. These myths may have reinforced the association between psychiatric symptoms and the lunar cycle that existed in the past.

Although our study provides a compelling explanation for the discrepancies in lunar research, it is the first of its kind and has several limitations. We chose three of the more commonly used definitions, but there are others that we did not test, such as a 6-hour, 7-day, and a lunar quartile model. Future research should include these alternate definitions of the full moon period. We also only looked at data from one centre and at psychiatric admissions. Future studies may wish to look at more centers and different diagnoses (such as maternity admissions).

\section{Conclusions}

This study found differences in psychiatric ED admissions during the full moon period, depending on the definition of "full moon." Our findings highlight the need for a consistent definition of "full moon." This lack of a consistent definition of the full-moon period may explain the conflicting findings of previous studies in this area.

\section{Conflict of Interests}

The authors have no financial or other conflict of interests to disclose.

\section{References}

[1] C. L. Raison, H. M. Klein, and M. Steckler, "The moon and madness reconsidered," Journal of Affective Disorders, vol. 53, no. 1, pp. 99-106, 1999.

[2] S. M. R. Kazemi-Bajestani, A. Amirsadri, S. A. A. Samari, and A. Javanbakht, "Lunar phase cycle and psychiatric hospital emergency visits, inpatient admissions and aggressive behavior," Asian Journal of Psychiatry, vol. 4, no. 1, pp. 45-50, 2011.

[3] J. Rotton and I. W. Kelly, "Much ado about the full moon. a meta-analysis of lunar-lunacy research," Psychological Bulletin, vol. 97, no. 2, pp. 286-306, 1985.

[4] D. F. Danzl, "Lunacy," Journal of Emergency Medicine, vol. 5, no. 2, pp. 91-95, 1987.

[5] R. N. McLay, A. A. Daylo, and P. S. Hammer, "No effect of lunar cycle on psychiatric admissions or emergency evaluations," Military Medicine, vol. 171, no. 12, pp. 1239-1242, 2006.

[6] S. F. Bauer and E. J. Hornick, "Lunar effect on mental illness: the relationship of moon phase to psychiatric emergencies," The American Journal of Psychiatry, vol. 125, no. 5, pp. 696-697, 1968.

[7] J. J. Gorvin and M. S. Roberts, "Lunar phases and psychiatric hospital admissions," Psychological Reports, vol. 75, no. 3, pp. 1435-1440, 1994.

[8] F. Amaddeo, G. Bisoffi, R. Micciolo, M. Piccinelli, and M. Tansella, "Frequency of contact with community based psychiatric services and the lunar cycle: a 10 year case-register study," Social Psychiatry and Psychiatric Epidemiology, vol. 32, no. 6, pp. 323-326, 1997.

[9] S. Núñez, L. Pérez Méndez, and A. Aguirre-Jaime, "Moon cycles and violent behaviours: myth or fact?" European Journal of Emergency Medicine, vol. 9, no. 2, pp. 127-130, 2002.
[10] C. Owen, C. Tarantello, M. Jones, and C. Tennant, "Lunar cycles and violent behaviour," Australian and New Zealand Journal of Psychiatry, vol. 32, no. 4, pp. 496-499, 1998.

[11] D. I. Templer and D. M. Veleber, "The moon and madness: a comprehensive perspective," Journal of Clinical Psychology, vol. 36, no. 4, pp. 865-868, 1980.

[12] J. Tasso and E. Miller, "The effects of the full moon on human behavior," Journal of Psychology, vol. 93, no. 2, pp. 81-83, 1976.

[13] W. Barr, "Lunacy revisited: the influence of the moon on mental health and quality of life," Journal of Psychosocial Nursing and Mental Health Services, vol. 38, no. 5, pp. 28-35, 2000.

[14] A. L. Lieber, "Human aggression and the lunar synodic cycle," Journal of Clinical Psychiatry, vol. 39, no. 5, pp. 385-392, 1978.

[15] F. Espenak, "Phases of the moon: 2001-2005," The NASA Eclipse Website, 2008, http://eclipse.gsfc.nasa.gov/phase/phase2001est .html.

[16] R. G. Foster and T. Roenneberg, "Human responses to the geophysical daily, annual and lunar cycles," Current Biology, vol. 18, no. 17, pp. R784-R794, 2008.

[17] G. Zanchin, "Macro and microcosmus: moon influence on the human body," Earth, Moon and Planets, vol. 85-86, pp. 453-461, 1999. 


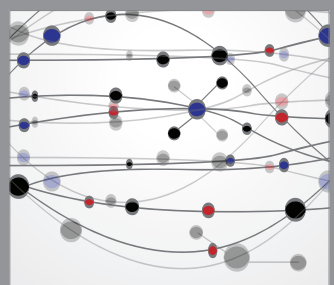

The Scientific World Journal
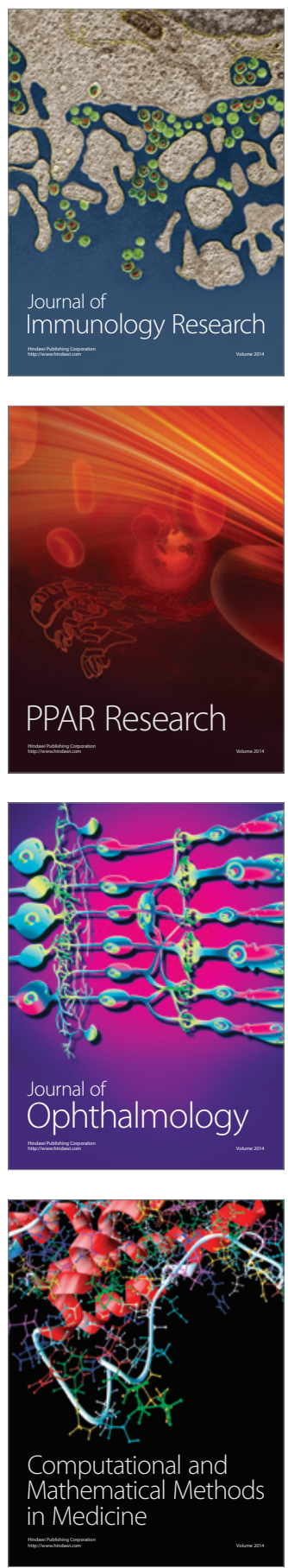

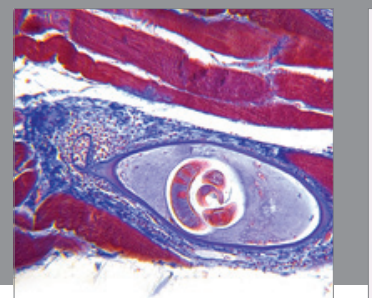

Gastroenterology

Research and Practice
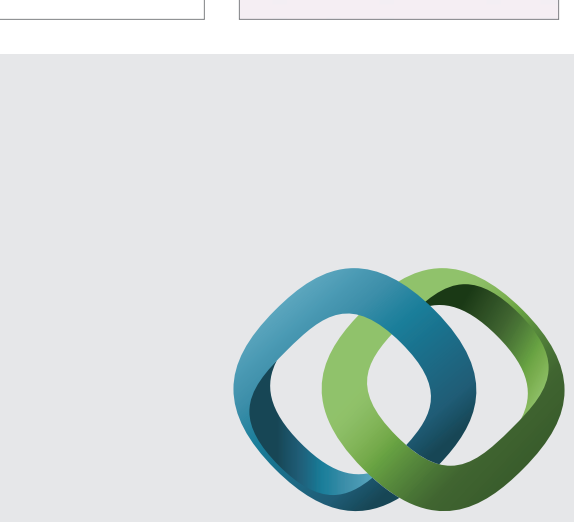

\section{Hindawi}

Submit your manuscripts at

http://www.hindawi.com
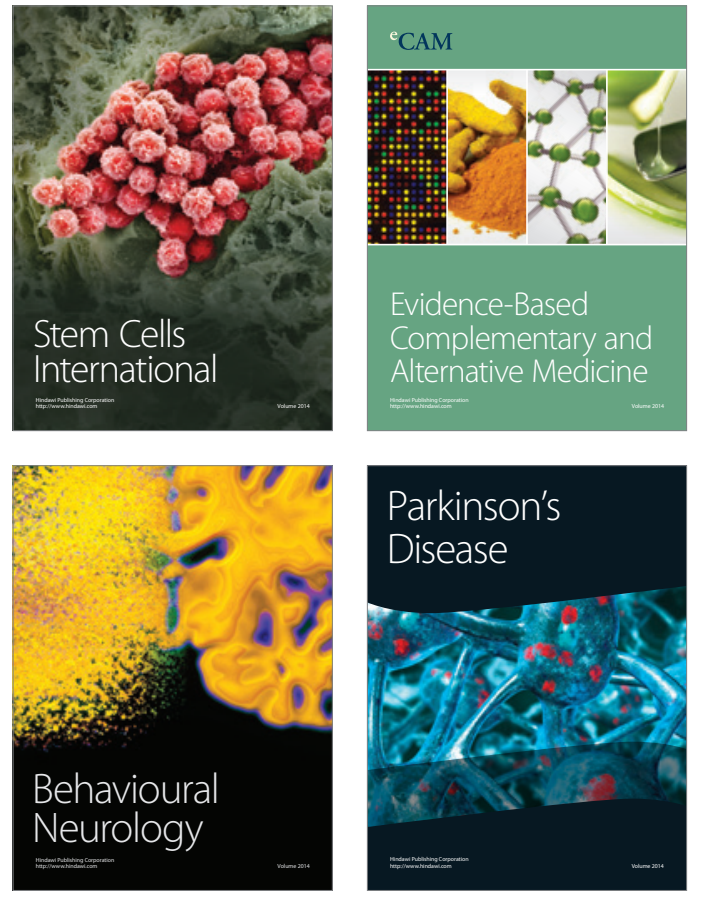
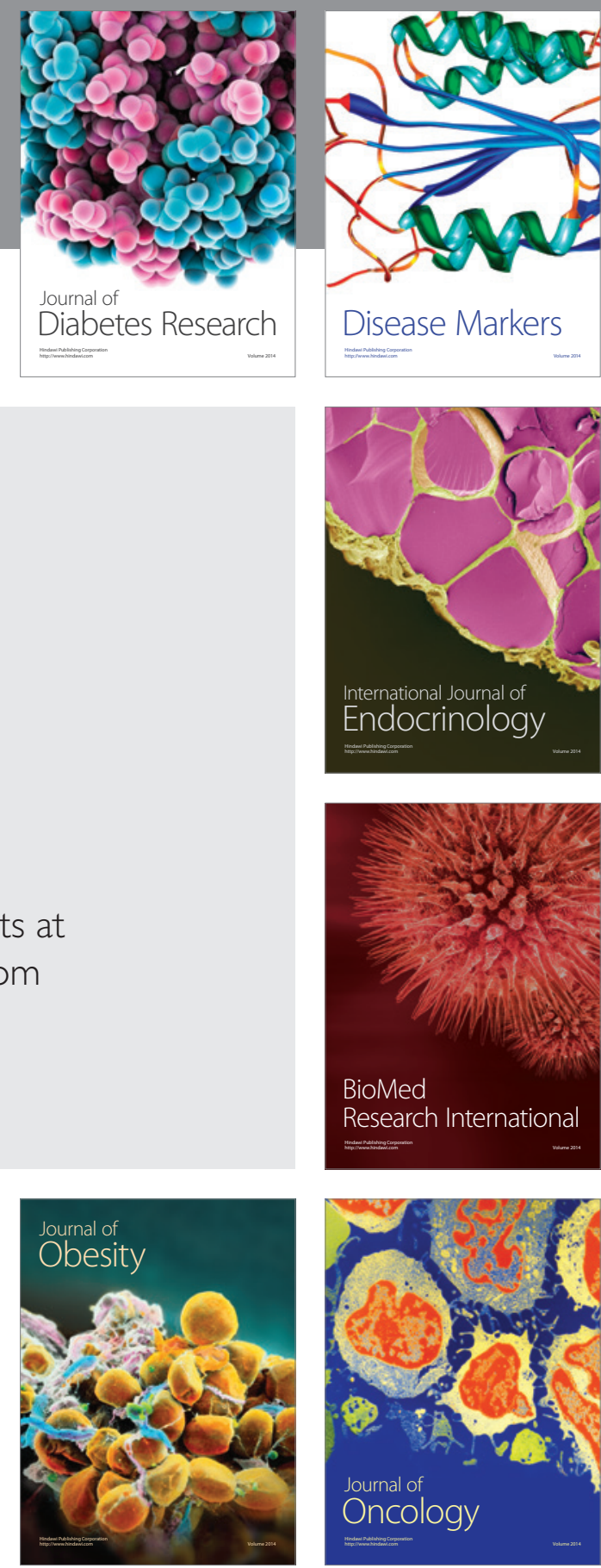

Disease Markers
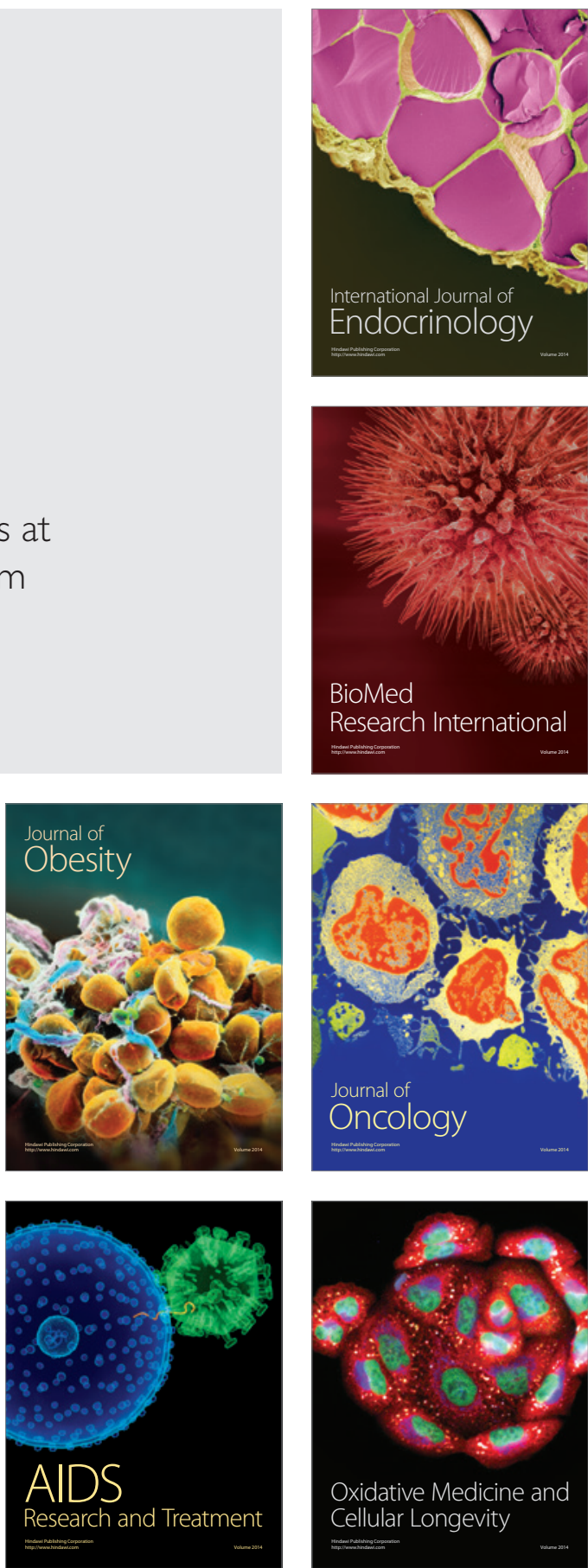